\title{
Vector Transmission of Xylella fastidiosa to Dormant Grape
}

R. P. P. Almeida, Department of Plant and Environmental Protection Sciences, University of Hawaii at Manoa, Honolulu 96822; C. Wistrom, Department of Environmental Science, Policy, and Management, University of California, Berkeley 94720; B. L. Hill, California Department of Food and Agriculture, Sacramento 95814; J. Hashim, University of California Cooperative Extension, Bakersfield 93307; and A. H. Purcell, Department of Environmental Science, Policy, and Management, University of California, Berkeley 94720

\begin{abstract}
Almeida, R. P. P., Wistrom, C., Hill, B. L., Hashim, J., and Purcell, A. H. 2005. Vector transmission of Xylella fastidiosa to dormant grape. Plant Dis. 89:419-424.

Homalodisca coagulata (Say) is a sharpshooter leafhopper vector of the bacterial plant pathogen Xylella fastidiosa. Introduced into California about 15 years ago, this insect triggered recent outbreaks of Pierce's disease of grapevine in the state. H. coagulata has been observed feeding on dormant grapevines during the winter, raising the possibility of $X$. fastidiosa transmission during that season. We tested whether $H$. coagulata can acquire $X$. fastidiosa from and inoculate the bacterium to dormant grape (Vitis vinifera) in the laboratory and in the field. Usually, $>90 \%$ of $H$. coagulata survived on dormant plants in the laboratory and field. Field experiments showed that $H$. coagulata can inoculate $X$. fastidiosa into dormant plants, yet field acquisition experiments did not result in transmission. Transmission to dormant plants during the winter is a potential problem in California vineyards adjacent to citrus groves or other habitats with large overwintering populations of $H$. coagulata. Because dormant plants have positive root pressure, our findings provide evidence that $X$. fastidiosa transmission does not require negative pressure in plant xylem to be inoculated into plants.
\end{abstract}

Additional keywords: glassy-winged sharpshooter

Pierce's disease of grapevines (PD), caused by the bacterium Xylella fastidiosa (10), is an example of how crop-vectorpathogen synchrony strongly influences pathogen dissemination. In coastal California, Graphocephala atropunctata, the blue-green sharpshooter (Hemiptera, Cicadellidae), a leafhopper that overwinters as adults in riparian areas adjacent to vineyards (22), is the major vector of $X$. fastidiosa $(14,21)$. In early spring, infective G. atropunctata individuals disperse from riparian areas to nearby vineyards to feed on succulent new grape shoots. These vectors transmit $X$. fastidiosa to grape from late March through May, initiating chronic (persistent) PD infections $(21,26)$. Almost no infection occurs from late May through June, because overwintering adults have

Corresponding author: A. H. Purcell E-mail: purcell@ nature.berkeley.edu

This research was partially supported by the United States Department of Agriculture (CSREES) grant no. 2001-3442-10406, American Vineyard Foundation grant no. V300 administered by California Department of Food and Agriculture, the Temecula Valley Winegrowers Association, and a scholarship from $\mathrm{CNPq}$ (Brazil) for R. P. P. Almeida. This work was part of R. P. P. Almeida's Ph.D. dissertation.

Accepted for publication 2 December 2004.

DOI: 10.1094/PD-89-0419

(C) 2005 The American Phytopathological Society died and the new generation of sharpshooters (from eggs laid in riparian zone) has not yet matured into flying adults (11). After June, G. atropunctata adults may be found throughout vineyards and successfully transmit $X$. fastidiosa, but few chronic infections result $(12,23)$. These late-season (June to September) inoculations of leaves or the growing tips of canes, where $G$. atropunctata prefers to feed, do not generate chronic disease because late-season infections usually recover or are removed by pruning during the winter $(12,17)$.

During the winter, grape plants are in a dormant state that protects meristematic tissues from desiccation and freezing injury. Late in the year, leaves abscise and water is withdrawn from xylem vessels that eventually fill with air (27). At the end of the winter, as soil temperatures increase, the grapevine refills its xylem vessels with sap by a mechanism as yet undetermined (31), but apparently requiring positive root pressure. Through this process, inorganic and organic nutrients are provided to lateral and apical meristems to permit resumption of shoot growth. Xylem exudates from plants with positive root pressure may vary from sap obtained in vessels during shoot growth, mostly in the proportion of organic and inorganic compounds present (4-6).

Introduction of an exotic species may destabilize the equilibrium of established pathosystems, changing disease dynamics
(32). The introduction of Homalodisca coagulata, the glassy-winged sharpshooter (Hemiptera, Cicadellidae), into California in $1989(9,30)$ had disastrous consequences to the grape-growing area of Temecula Valley, Riverside County $(9,17)$. This sharpshooter is the vector of X. fastidiosa in current PD epidemics in southern and central California, threatening grape, almond, oleander, and alfalfa. Other strains of $X$. fastidiosa could affect peach, plum, and citrus should they be introduced into the state $(17,24)$. In contrast to $G$. atropunctata, $H$. coagulata individuals feed on and transmit $X$. fastidiosa to woody tissues of grape and almond $(2,3,26)$, overwinter as active adults, and can feed on dormant vines during the winter months $(8,9)$. This may allow inoculations that occur in fall or winter months to establish chronic disease, because these infections could occur in mature sections of the plant that are not pruned off, or that might survive in dormant wood during the winter (12).

Because of the possible epidemiological implications of $X$. fastidiosa acquisition and inoculation during the winter by $H$. coagulata and the different physiological states and environmental conditions between dormant and growing vines, we studied the possibility that this leafhopper could transmit $X$. fastidiosa to dormant grape plants in the field and laboratory. We have reported previously that $H$. coagulata transmits $X$. fastidiosa to dormant almond plants under laboratory conditions (3).

\section{MATERIALS AND METHODS}

Greenhouse, insect, bacterium, and plants. The greenhouse at the University of California in Berkeley, where experiments were conducted, had three separate rooms designated (i) insectary $\left(25 \pm 5^{\circ} \mathrm{C}\right)$, where insects were kept and transmission experiments conducted; (ii) cool room (20 $\pm 2^{\circ} \mathrm{C}$ ), where plants were maintained for development of positive root pressure and new shoot elongation; and (iii) incubation room $\left(25 \pm 5^{\circ} \mathrm{C}\right)$, in which plants were maintained for symptom development. Source plants that were infected with $X$. fastidiosa, as confirmed by culture assay, had PD foliar symptoms (unless dormant). Pre-test plants were healthy young grapevines on which insects were fed to identify naturally infected $H$. coagulata groups. 
Test plants were healthy grapevines used to determine whether insects were infective after acquisition of $X$. fastidiosa from a source plant.

H. coagulata individuals used for experiments were collected on sweet orange (Citrus sinensis) or on a Eucalyptus sp. wind barrier between citrus groves south of Highway CA-58 near General Beale Road, Bakersfield, Kern County during late fall and winter of 2001-02. These insects were probably first- and second-generation adults overwintering in the area. After collection, we transported the insects to Berkeley and kept them in an insectary in Plexiglas cages with mugwort, basil, grape, and okra as host plants. We used individuals reared in laboratory colonies for experiments conducted in 2002-03. General insect handling protocols and cages used have been described previously (2). Source plants, self-rooted Cabernet Sauvignon and Pinot Noir grapevine cuttings, had been infected at least 3 to 4 months earlier by mechanical inoculation (15), and were symptomatic at time of use unless dormant. Healthy grapevine cultivars for laboratory transmission experiments were Cabernet Sauvignon and Pinot Noir seedlings and cuttings; both cultivars are susceptible to $X$. fastidiosa (23). We used the $X$. fastidiosa isolate STL (American Type Culture Collection [ATCC] 700963), originally isolated from a grapevine in Napa Valley, for all experiments. Transmission tests in Berkeley were done in a greenhouse insectary under natural light conditions, unless noted below. Transmission experiments were conducted in the months of January, February, and March 2002 and 2003. After insects were taken from test plants, all grapevines were kept in an insect-free incubation room at the same facility for up to 6 months for symptom development. Dormant plants were kept in the cool room for the development of positive root pressure after insect access but before shoots emerged (described below). After this period, dormant plants were transferred to the incubation room.

$X$. fastidiosa detection. We assayed plants for infection by $X$. fastidiosa using the culture method described by Hill and Purcell (16). Briefly, petiole samples were collected 2 to 4 months after insect inoculation, surface sterilized, cut into approximately 1-mm-diameter sections, and finely ground in a tissue homogenizer (Brinkman Polytron with PT-10S generator). Suspensions were plated on modified periwinklewilt medium (PWG; 16). Routine confirmation of bacterial colonies as $X$. fastidiosa was done by polymerase chain reaction (PCR) using the primers RST31 and RST33 (19). All colonies tested were confirmed as $X$. fastidiosa. In 2003, plants that had $H$. coagulata access during inoculation experiments in the field also were tested by PCR. Enzyme-linked immu- nosorbent assay (ELISA; 15) conducted by the diagnostics laboratory of the California Department of Food and Agriculture (Sacramento) was used for diagnosis of all field-collected samples in 2002 and 2003.

Dormant plants. Cabernet Sauvignon and Pinot Noir rooted cuttings, maintained in 3.8-liter pots during the spring through fall inside the greenhouse, were used for dormant grapevine transmission experiments. In October 2001 and 2002, healthy and diseased plants were moved to screened cages outdoors, where plants were watered as necessary. After leaf abscission, the potted grape plants were pruned and, in January, they were moved to a cold box $\left(4^{\circ} \mathrm{C}\right)$. Plants kept in the cold box were sprayed periodically with Elite 45 WP fungicide (Bayer Corp., Kansas City, MO) in 2001 when mold was observed on some grapevines. Four days before insect access began, we moved the grapevines to the cool room for development of positive root pressure. We found that $H$. coagulata did not survive if caged on dormant plants immediately after taking the grapevines outside the cold box but survived well if we waited until the plants exuded sap when pricked with a \#0 entomological pin, approximately 4 days after we brought them inside, regardless of the size of the vine. The sap exuded by cut plants dried to a white residue 5 to 10 days after cutting. Thus, we assumed that plants had positive root pressure and xylem vessels were at least partially filled with sap when insects had access to them.

Laboratory acquisition experiment. Field-collected $H$. coagulata were divided into groups of four to five individuals and confined in mesh fabric sleeve cages surrounding grape seedlings for 4 days to test for $X$. fastidiosa presence in the leafhoppers (for identification of naturally infective insects). Only $H$. coagulata that tested $X$. fastidiosa-free on pre-test plants were used in our experiments, with one exception described in the Results section. Thirty-four insect groups were used; four repetitions (variable number of insect groups used per repetition) of the experiment were done. We then transferred the groups to dormant grape as $X$. fastidiosa sources (using the same cages) for an acquisition access period (AAP; during this period, insects feed and can acquire $X$. fastidiosa from a PD-infected plant) of 4 days in a growth chamber $\left(17^{\circ} \mathrm{C}\right.$; photoperiod, $14 \mathrm{~h}$ of light and $10 \mathrm{~h}$ of darkness). These insects then were moved in groups to a test plant for a 4-day inoculation access period (IAP; during this period, insects fed and could inoculate $X$. fastidiosa into a healthy plant) in the insectary (Fig. 1). The test plants were sprayed with Provado insecticide (Bayer Corp.) at 120 ppm after the insects were removed, and then moved to the incubation room for symptom development. We maintained the dormant source plants in the cool room until new shoots started to grow, then transferred them to the incubation room. All dormant source plants used for acquisition studies were kept to confirm that PD symptoms developed. Four repetitions of the experiment were pooled to obtain the number of groups tested presented. A $\chi^{2}$ test (1) was used to determine whether insects acquired $X$. fastidiosa from dormant source plants at a significantly different rate than negative controls (pre-test plants, used to determine natural infectivity).

Some of the same insect groups were used later to test $X$. fastidiosa acquisition from growing (nondormant) source plants kept in the greenhouse during the winter. This assay was a control for insect transmissibility of $X$. fastidiosa during the winter, with access in the greenhouse to actively growing source plants compared with access to dormant source plants. Thus, 15 groups (from two repetitions of the experiment) of $H$. coagulata had an additional 4-day AAP on PD source plants maintained inside the greenhouse during the winter. These groups later were transferred to a new, actively growing test grapevine for a 4-day IAP (Fig. 1).

Laboratory inoculation experiment. Adult $H$. coagulata were given a 4-day AAP on nondormant PD source vines maintained in the greenhouse during the winter, then transferred in groups of four individuals for 4 days of IAP on growing grape seedlings maintained in the greenhouse. This allowed us to estimate retrospectively which $H$. coagulata groups were capable of transmitting $X$. fastidiosa. We then transferred all groups to dormant test plants for two or three successive 4day IAPs, each on a different dormant plant (Fig. 1). We used the same growth chamber as for the acquisition experiments. After the IAP, plants were maintained in the cool room until they broke dormancy and then were moved to the incubation room. The experiment was repeated nine times with different number of plants used per repetition (dependent on insect and plant availability) and the results pooled.

Field acquisition experiment. We conducted an acquisition experiment during January 2003 in the same cage where inoculation experiments were performed (see below) to determine whether $H$. coagulata could acquire $X$. fastidiosa from infected dormant grape plants in the field. Dormant plants that were successfully inoculated by $H$. coagulata groups in the 2002 winter tests served as sources of $X$. fastidiosa. Fifteen groups of four laboratory-reared $H$. coagulata adults were caged on pre-test grape plants in the greenhouse for a 7-day IAP to determine whether all insects were free of $X$. fastidiosa. After the IAP, we transferred the insects for a 7-day AAP on source plants in the field. Groups of survivors were removed from the dormant plant 
and transferred to healthy test grape plants which were brought back to the insectary greenhouse in Berkeley for a 7-day IAP (Fig. 1). Insects were removed after IAP, and the plants were sprayed and moved to the incubation room. For the March 2004 test, we used insects reared in an insectary in Kern County, CA by the California Dept. of Food and Agriculture. Six dormant source plants were used for the 2004 repetition of the experiment.

Field inoculation experiment. We conducted the field trial in a screened cage in Bakersfield, CA. The cage was archshaped, $30 \mathrm{~m}$ long, $2.5 \mathrm{~m}$ wide, and $1.8 \mathrm{~m}$ high. It was covered with plastic mesh screen to exclude possible $X$. fastidiosa vectors and other pests and a drip irrigation system was installed in the center of the cage. Cultural practices were similar to those used by growers in California. In September 2001, we planted 92 rooted 1year-old Pinot Noir grapevines inside the cage, and 20 outside the cage to detect the possible impact of the screen on plant development.

Insects were field collected 1 to 2 weeks before each experiment. For one set of inoculations (8 May 2002, described below), we used insects reared from eggs in the greenhouse, because wild populations of $H$. coagulata were drastically reduced due to natural mortality and countywide insecticide sprays. Groups of four $\mathrm{H}$. coagulata adults were confined for a 4-day AAP on green STL sources and were transferred to test plants for a 7-day IAP in the greenhouse. We transported these groups to Bakersfield and transferred them to randomly chosen dormant grapevines inside the cage for a 7-day IAP (Fig. 1). We returned the test plants to the Berkeley greenhouse incubation room for symptom development. We caged insects on dormant grape canes with fabric sleeve cages ( 30 by $10 \mathrm{~cm}$ ). To avoid collapse of the sleeve cages onto the sharpshooters due to rain and wind, we positioned cylinders cut from transparent plastic bottles to enclose that portion of the cane on which the insects were feeding. After the 7-day IAP ended, we counted the number of survivors and killed insects inside the cages to avoid escape of individuals into the screen cage. Inoculations in Bakersfield were set up on 8, 21, and 28 February and 8 May 2002. The May inoculation was done on new shoot growth as a positive control to confirm $H$. coagulata transmission to our growing vines. We inoculated 25, 18, 20, and 13 plants per period, respectively. Sixteen plants were maintained as negative controls, without any insect access. We did not have the same number of plants in each period due to insect mortality during the winter. Temperatures were monitored at the location with a digital recorder (Hobo; Onset Computer Corporation, Bourne, MA) located inside the cage. Sample leaves were collected in the field and tested by ELISA on 10 September and 24 October 2002.

We repeated the experiment the following year (2002-03), with minor changes in the experimental design. We had a limited number of plants in the cage for a repetition because we had to wait until fall 2002 to determine whether insects had transmitted $X$. fastidiosa to dormant plants during the previous winter. We assumed that all $X$. fastidiosa-negative plants in 2002 were uninfected. We kept 16 negative control plants without insect access in 2002 and 2003 and, in 2003, added a new set of negative controls to the experiment. The latter were plants that had insect access and tested negative in 2002. Plants that were positive for X. fastidiosa in 2002 were not used for the 2003 experiments.

In 2003, we did two inoculation experiments in the field which started on 23 and 30 January. We used 15 groups of four $H$. coagulata insects. Laboratory-reared individuals were used due to low populations of insects in the wild in 2003. General methods were the same as those used for the 2002 experiments. No inoculations of actively growing green vines were repeated during spring 2003 .

\section{RESULTS}

Laboratory acquisition experiment. Of $30 \mathrm{H}$. coagulata groups, 5 transmitted $X$. fastidiosa to test plants after acquisition on dormant plants. Most likely, none of these groups were previously carrying $X$. fastidiosa, because none infected their respective pre-test plants. Of 34 groups of sharpshooters, 4 died during AAP on dormant source plants, leaving 30 groups for 4 days of IAP on test grape. One group that

Laboratory $-X$. fastidiosa acquisition from dormant plants

\begin{tabular}{|c|c|c|c|c|c|c|c|c|}
\hline $\begin{array}{c}\text { Pre-test } \\
\text { green plant }\end{array}$ & $4 d$ & $\begin{array}{c}\text { AAP } \\
\text { dormant plant }\end{array}$ & $4 \mathrm{~d}$ & $\begin{array}{c}\text { IAP } \\
\text { green plant }\end{array}$ & $4 \mathrm{~d}$ & $\begin{array}{c}\text { AAP } \\
\text { green plant }\end{array}$ & $4 d$ & $\begin{array}{c}\text { IAP } \\
\text { green plant }\end{array}$ \\
\hline
\end{tabular}

Field - X. fastidiosa acquisition from dormant plants

\begin{tabular}{|c|c|c|c|c|}
\hline $\begin{array}{l}\text { Pre-test } \\
\text { green plant }\end{array}$ & $7 d$ & $\begin{array}{c}\text { AAP-field } \\
\text { dormant plant }\end{array}$ & $7 \mathrm{~d}$ & $\begin{array}{c}\text { IAP } \\
\text { green plant }\end{array}$ \\
\hline
\end{tabular}

Laboratory $-X$. fastidiosa inoculation into dormant plants

\begin{tabular}{|c|c|c|c|c|}
\hline $\begin{array}{c}\text { AAP } \\
\text { green plant }\end{array}$ & $4 d$ & $\begin{array}{c}\text { IAP } \\
\text { green plant }\end{array}$ & $4 d$ & $\begin{array}{c}\text { IAP } \\
\text { dormant plant }\end{array}$ \\
\hline
\end{tabular}

Field - X. fastidiosa inoculation into dormant plants

\begin{tabular}{|c|c|c|c|c|}
\hline $\begin{array}{c}\text { AAP } \\
\text { green plant }\end{array}$ & $4 d$ & $\begin{array}{c}\text { IAP } \\
\text { green plant }\end{array}$ & $7 \mathrm{~d}$ & $\begin{array}{c}\text { IAP-field } \\
\text { dormant plant }\end{array}$ \\
\hline
\end{tabular}

Fig. 1. Flow charts summarize experimental designs used. Boxes represent plants on which insects were caged for various periods of time (number of days above arrows after box). Dormant plants are shown as shaded boxes with bold font. Green plants were grapevines maintained under greenhouse conditions throughout an experiment. Laboratory and field flow charts indicate where insects had access to dormant plants; all other plant access periods occurred in the greenhouse. 
did not survive the AAP transmitted to the pre-test plant; thus, at least one individual of that group was naturally infective. The difference between transmission to pre-test and test plants was not significant $\left(\chi^{2}, P>\right.$ $0.05,1 \mathrm{df})$, but a $\chi^{2}$ test was inappropriate for such a small number of positive transmissions. Some $H$. coagulata groups $(n=$ 15) also had a second AAP on green nondormant source plants as a positive control to demonstrate that the cohorts used could acquire $X$. fastidiosa from growing plants under the same conditions as dormant plants. Of the 15 groups, 11 transmitted to a test plant after AAP on a green source. All dormant source plants became symptomatic with PD later in the year. Overall, $75 \%$ of $H$. coagulata survived AAP on dormant sources, compared with $90 \%$ survival on dormant plants without $X$. fastidiosa. The mortality during AAP may have been due to a longer period required for positive root pressure to fill xylem vessels in the four $X$. fastidiosainfected source plants because of bacterial-induced blockage of the xylem.

Laboratory inoculation experiment. $H$. coagulata transmitted $X$. fastidiosa to dormant grape plants under laboratory conditions (Table 1). Of the insect groups studied, 44\% acquired $X$. fastidiosa after AAP on green PD-symptomatic grapevines, as determined by transmission to grape seedlings after acquisition. In all, 8 of $84(9.4 \%) X$. fastidiosa-carrying insect groups transmitted $X$. fastidiosa to dormant plants. Buds on dormant grapevines began to swell 7 to 10 days and new shoot extension 12 to 16 days after being brought out of the $4^{\circ} \mathrm{C}$ cold box. Survival of $H$. coagulata was high $(94.7 \%)$ on dormant plants (Table 1), demonstrating that this species can survive on dormant plants with positive root pressure in the greenhouse.

Field acquisition experiment. After a 7-day AAP on dormant plants in the field, none of the 15 groups transmitted $X$. fastidiosa to test plants in the greenhouse. All $15 \mathrm{H}$. coagulata groups were shown to be $X$. fastidiosa-free in the greenhouse prior to access to dormant grape plants in the field. Only $50 \%$ of the insects survived the AAP on dormant plants in the field. Of the 15 plants used as source plants, 14 were dead from PD by October 2003. This experiment was repeated in the first week of March 2004 with six infected plants used

Table 1. Summary of laboratory inoculation experiments to dormant grapevines with groups of four Homalodisca coagulata individuals per plant

\begin{tabular}{lc}
\hline Experiment & Number \\
\hline Experiment repetitions & 9 \\
Grape pre-test plants & 89 \\
Infected grape pre-test plants & 39 \\
Dormant plants with access by infective groups & 84 \\
Dormant plants inoculated with Xylella fastidiosa by infective groups & 8 \\
Total no. of $H$. coagulata in experiments & 354 \\
Overall $H$. coagulata survival rate on pre-test plants & $89.8 \%$ \\
Overall $H$. coagulata survival rate on dormant plants & $94.7 \%$ \\
\hline
\end{tabular}

as sources in the field; insects did not transmit $X$. fastidiosa to test plants in the laboratory after AAP on these dormant vines.

Field inoculation experiment. We inoculated dormant vines in the field with infective $H$. coagulata on four dates, three in February 2002 and one during May 2002. On average, $68 \%$ of insect groups that transmitted $X$. fastidiosa to test plants in the greenhouse also infected dormant vines in the field during February of 2002 (all three inoculation experiments pooled together, $n=13$ positive plants in the field; Fig. 2). Half of the four groups that proved to have been infected transmitted to plants in the field during the May inoculation (Fig. 2).

All but one of the ELISA-positive samples also had typical PD symptoms. All negative control plants, which had no insect access at any time, were negative for $X$. fastidiosa and had no PD symptoms. Insect survival was $80,94,47$, and $86 \%$ for the 8,21 , and 28 February and 8 May 2002, inoculations, respectively. Insect survival was above $85 \%$ for both repetitions in 2003. During the winter 2002 inoculations, freezing temperatures (temperature range of -1 to $1^{\circ} \mathrm{C}$ ) occurred during all winter inoculations, and maximum temperatures were usually higher than $25^{\circ} \mathrm{C}$ during these periods (average daily minimum, $1.0 \pm 0.34^{\circ} \mathrm{C}$; average daily maximum, $26.4 \pm 0.77^{\circ} \mathrm{C}$ ).

Plants started to show symptoms in August, and all three plants with initial PD symptoms were positive by culturing for $X$. fastidiosa. ELISA tests in October identified one additional $X$. fastidiosa-infected plant. Symptom severity varied from only foliar symptoms to dead or nearly dead

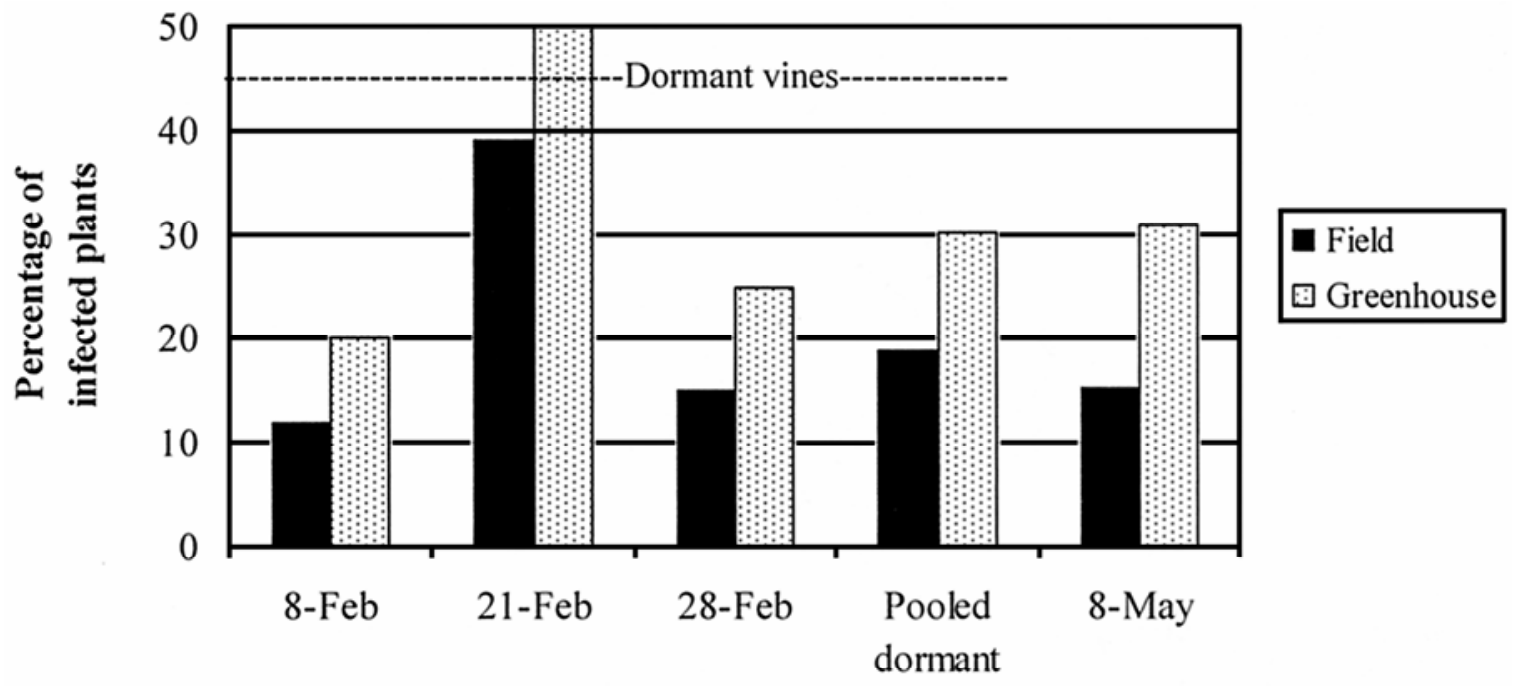

\section{Date of inoculation}

Fig. 2. Percentage of infective plants after Homalodisca coagulata inoculation of Xylella fastidiosa into grapevines planted in the field and potted seedlings in the greenhouse during the 2002 winter. Results of inoculation into dormant plants in the field were pooled under 'Pooled dormant'. The 8 May inoculation was a positive control to demonstrate that field plants kept under similar conditions during the spring could be inoculated with $X$. fastidiosa by $H$. coagulata. 
branches without leaves and petioles. No negative control plants were positive, including those that never had insect access and those on which insects fed during the 2002 experiments. The 10 grapevines planted outside the screen cage did not notably differ in phenology compared with those inside the cage, and none had PD symptoms in 2002 or 2003 . The 2003 winter repetition of the experiment had transmission rates similar to those in 2002 with both greenhouse- and field-maintained plants. In all, 7 of $30(23 \%) H$. coagulata groups transmitted to test plants in the greenhouse, and 3 of those 7 groups transmitted to dormant plants in the field. No negative control plants were positive, including those that never had insect access and those on which insects fed in the 2002 experiments.

\section{DISCUSSION}

$H$. coagulata is a vector of $X$. fastidiosa and has been observed feeding on dormant grapevines in the field. Therefore, we conducted this investigation to determine whether $H$. coagulata could acquire and inoculate the bacterium to dormant grapevines under both controlled and field conditions. Our results demonstrated that overwintering adults can transmit $X$. fastidiosa to dormant vines. We found that $H$. coagulata transmitted $X$. fastidiosa to dormant grape plants in the laboratory and in the field. We also found evidence that $H$. coagulata can acquire $X$. fastidiosa from dormant plants in the greenhouse, but our field tests of acquisition from infected grape were negative. Further studies with a greater number of insects, done under both laboratory and field conditions, will be necessary to determine whether $H$. coagulata acquires $X$. fastidiosa from dormant plants at rates lower than our experiments were designed to detect with reasonable confidence $(P<0.05)$. Insects survived well on dormant plants in both environments, even though almost freezing temperatures occurred frequently during the field experiment.

Most grapevines in northern California with PD established by spring inoculations do not recover (i.e., become $X$. fastidiosafree the following season) after a normal winter (12). The reasons for overwinter recovery are not known. Our data suggest that acquisition of $X$. fastidiosa from dormant plants by $H$. coagulata may occur, although we were not able to test enough plants in the laboratory to obtain statistically robust results. Our field experiment resulted in no acquisition of the bacterium from dormant plants, but this finding requires confirmation because the number of insects tested was low. Despite the theoretical implications of the possible bacterial acquisition during the winter, its importance to PD spread may be small because control practices recommend removal of infected vines upon first identifi- cation. In January 2003, we conducted a similar acquisition experiment on almond orchards; none of 16 groups of four $H$. coagulata individuals acquired $X$. fastidiosa in that test, but insect survival was low on dormant almond compared with grape plants (16 of 64 individuals survived 1 week AAP on almond in the field; unpublished data).

Transmission to dormant plants in the field and greenhouse consistently occurred at lower rates than to green plants. The low transmission rates may be due to poor bacterial survival in dormant plants, which are physiologically and biochemically different from actively growing plants, or to a response to decreased survival of the bacterial infection at temperatures below $10^{\circ} \mathrm{C}$ (13). X. fastidiosa survives winter in infections that occurred the previous growing season, but the fluctuations of bacterial populations during this process are unknown. Theoretically, only a few cells of $X$. fastidiosa that survive the winter should be enough to generate an infection the following year.

Another factor that may lower transmission efficiency to dormant plants is the feeding behavior of $H$. coagulata. Xylem sap is pushed upward (distally) from the roots in stems of dormant grape. Successful inoculation of $X$. fastidiosa into dormant plants is indirect evidence that transmission requires active release of bacteria by the vector during feeding. Previous $X$. fastidiosa transmission studies $(25,28,29)$ have been done with green plants, which normally have negative xylem pressure during transpiration. Under these conditions, when the insect's stylet penetrates a xylem vessel, fluid present in the mouthparts, most likely distally to or near the precibarial valve (7), might be transiently pulled into the plant due to lower negative potential within the xylem stream. X. fastidiosa could be sucked into the xylem stream by the lower pressure compared with that in the stylet food canal of the feeding vector. In contrast, positive root pressure sap in dormant plants would preclude a passive withdrawal of $X$. fastidiosa from the vector's foregut. To our knowledge, this aspect of sharpshooters' probing behavior has not been addressed, and it may be important in understanding vector transmission of $X$. fastidiosa.

In previous work, we found that $H$. coagulata can transmit $X$. fastidiosa to 2year-old woody stems of grape plants (2). Those results support the hypothesis that $H$. coagulata is a major threat to vineyards because inoculation into susceptible plants during the fall permits $X$. fastidiosa to move into mature wood and overwinter below winter pruning cuts, leading to chronic infections (17). Therefore, $\mathrm{H}$. coagulata control would be desirable any time the vector is present on green, actively growing vines. Our data show that dormant plants also may be at risk, but there are no field data to quantify the importance of feeding by $H$. coagulata during winter. Growers may have to control $H$. coagulata populations year-round to manage PD in vineyards visited by $H$. coagulata during winter.

The threat of $X$. fastidiosa inoculation of dormant plants in central California would be highest in vineyards near citrus groves (20), where individual citrus plants can harbor thousands of sharpshooters during the winter. Because these adult populations can feed on grape plants for brief periods of time during the winter, and short plant access periods are enough for transmission in actively growing plants (2), control of vectors within vineyards may have limited success. Lowering vector numbers on citrus should be a more successful strategy, because vector populations affect the probability of $X$. fastidiosa transmission to plants (23). The impact of this approach on currently implemented integrated pest management in citrus groves is currently under investigation.

We conducted some of the experiments described in this study in 2000 to 2002 and previously reported experiments in 2003 $(2,3)$ with $H$. coagulata that were collected from citrus orchards adjacent to PDinfected vineyards in the southern Central Valley. Overall, we tested more than three thousand individuals in the laboratory for $X$. fastidiosa natural infectivity in 2000 and 2001, but only one insect group transmitted the bacterium from insects collected in 2001 , leading to estimates that only one to three insects per thousand coming from citrus were naturally infectious. These results suggest that, currently, citrus is not an acquisition source for PD strains of $X$. fastidiosa in California. It also may be possible that $H$. coagulata individuals that arrive in citrus already infective with PD strains of $X$. fastidiosa are not vectoring isolates that can multiply in citrus. However, the citrus (citrus variegated chlorosis) or coffee strains of $X$. fastidiosa would become an important problem for PD in vineyards as well as for orange crops if they reach California because those strains multiply systemically in citrus and also cause PD (18). Thus, the threat posed to vineyards near citrus would increase because the numbers of $X$. fastidiosainfective $H$. coagulata should increase dramatically in citrus groves where these citrus-infecting strains occur.

Our findings suggest new areas for basic and applied research on $X$. fastidiosa. We now have evidence suggesting that vector transmission (at least to dormant grapevines) requires expulsion of $X$. fastidiosa from the foregut rather than passive transfer by suction from the plant; and that $X$. fastidiosa survives and causes disease if inoculated into dormant plants. Blua and Morgan (8) recently analyzed the dispersion of $H$. coagulata into vineyards yearround, and found that one peak of flight 
activity associated with citrus occurs during the winter, demonstrating that the winter season might be important for PD spread with $H$. coagulata. Estimating the importance of winter vector activity on the spread of PD will require further studies. Research will be needed to address questions regarding (i) the number of insects that visit dormant vines and for how long; (ii) the natural infectivity level of vector populations during the winter, where they acquire $X$. fastidiosa, and their inoculation efficiency; (iii) how successfully $X$. fastidiosa infections survive the winter; (iv) the impact of vector control on disease spread; and (v) the importance of infection events in areas with occasional or frequent warm winters.

\section{ACKNOWLEDGMENTS}

We thank E. Norberg, D. Chiniquy, and P. Juneja for technical assistance, suggestions, and revision of the manuscript; and S. Rill, CDFA, Arvin, CA, for providing laboratory-reared $H$. coagulata for our 2004 experiment.

\section{LITERATURE CITED}

1. Agresti, A., and Finlay, B. 1997. Statistical Methods for the Social Sciences. Prentice-Hall Inc., Upper Saddle River, NJ.

2. Almeida, R. P. P., and Purcell, A. H. 2003. Transmission of Xylella fastidiosa to grapevines by Homalodisca coagulata (Hemiptera: Cicadellidae). J. Econ. Entomol. 96:264-271.

3. Almeida, R. P. P., and Purcell, A. H. 2003. Homalodisca coagulata (Hemiptera, Cicadellidae) transmission of Xylella fastidiosa to almond. Plant Dis. 87:1255-1259.

4. Andersen, P. C., and Brodbeck, B. V. 1988. Water and solute fluxes through pruned muscadine grape spurs. HortScience 23:978-980.

5. Andersen, P. C., and Brodbeck, B. V. 1989. Temperature and temperature preconditioning on flux and chemical composition of xylem exudate from muscadine grapevines. J. Am. Soc. Hortic. Sci. 114:440-444.

6. Andersen, P. C., Brodbeck, B. V., and Mizell, R. F., III. 1992. Feeding by the leafhopper, Homalodisca coagulata, in relation to xylem fluid chemistry and tension. J. Insect Physiol. 38:611-622.

7. Backus, E. A., and McLean, D. L. 1982. The sensory systems and feeding behavior of leafhoppers. I. The aster leafhopper, Macrosteles fascifrons Stal (Homoptera, Cicadellidae). J. Morphol. 172:361-379.

8. Blua, M. J., and Morgan, D. J. W. 2003. Dispersion of Homalodisca coagulata (Hemiptera: Cicadellidae), a vector of Xylella fastidiosa, into vineyards in southern California. J. Econ. Entomol. 96:1369-1374.

9. Blua, M. J., Phillips, P. A., and Redak, R. A. 1999. A new sharpshooter threatens both crops and ornamentals. Calif. Agric. 53:22-25.

10. Davis, M. J., Purcell, A. H., and Thomson, S. V. 1978. Pierce's disease of grapevines: isolation of the causal bacterium. Science 199:75-77.

11. Feil, H., Feil, W. S., and Purcell, A. H. 2000. Effects of temperature on the flight activity of Graphocephala atropunctata (Hemiptera: Cicadellidae). J. Econ. Entomol. 93:88-92.

12. Feil, H., Feil, W. S., and Purcell, A. H. 2002. Effects of date of inoculation on the withinplant movement of Xylella fastidiosa and persistence of Pierce's disease within field grapevines. Phytopathology 93:244-251.

13. Feil, H., and Purcell, A. H. 2001. Temperaturedependent growth and survival of Xylella fastidiosa in vitro and in potted grapevines. Plant Dis. $85: 1230-1234$

14. Hewitt, W. B., Frazier, N. W., Freitag, J. H., and Winkler, A. J. 1949. Pierce's disease investigations. Hilgardia 19:207-264.

15. Hill, B. L., and Purcell, A. H. 1995. Multiplication and movement of Xylella fastidiosa within grapevine and four other plants. Phytopathology 85:1368-1372.

16. Hill, B. L., and Purcell, A. H. 1995. Acquisition and retention of Xylella fastidiosa by an efficient vector, Graphocephala atropunctata. Phytopathology 85:209-212.

17. Hopkins, D. L., and Purcell, A. H. 2002. Xylella fastidiosa: cause of Pierce's disease of grapevine and other emergent diseases. Plant Dis. 86:1056-1066.

18. Li, W. B., Zhou, C. H., Pria, W. D., Teixeira, D. C., Miranda, V. S., Pereira, E. O., Ayres, A. J., and Hartung, J. S. 2002. Citrus and coffee strains of Xylella fastidiosa induce Pierce's disease in grapevine. Plant Dis. 86:1206-1210.

19. Minsavage, G. V., Thompson, C. M., Hopkins,
D. L., Leite, R. M. V. B. C., and Stall, R. E. 1994. Development of a polymerase chain reaction protocol for detection of Xylella fastidiosa in plant tissue. Phytopathology 84:456461.

20. Perring, T. M., Farrar, C. A., and Blua, M. J 2001. Proximity to citrus influences Pierce's disease in Temecula Valley vineyards. Calif. Agric. 55:13-18.

21. Purcell, A. H. 1975. Role of the blue-green sharpshooter, Hordnia circellata, in the epidemiology of Pierce's disease of grapevines. Environ. Entomol. 4:745-752.

22. Purcell, A. H. 1976. Seasonal changes in host plant preference of the blue-green sharpshooter Hordnia circellata (Homoptera: Cicadellidae). Pan-Pac. Entomol. 52:33-37.

23. Purcell, A. H. 1981. Vector preference and inoculation efficiency as components of resistance to Pierce's disease in European grape cultivars. Phytopathology 71:429-435.

24. Purcell, A. H. 1997. Xylella fastidiosa, a regional problem or global threat? J. Plant Pathol. 79:99-105.

25. Purcell, A. H., and Finlay, A. H. 1979. Evidence for noncirculative transmission of Pierce's disease bacterium by sharpshooter leafhoppers. Phytopathology 69:393-395.

26. Purcell, A. H., and Saunders, S. R. 1999 Glassy-winged sharpshooters expected to increase plant disease. Calif. Agric. 53:26-27.

27. Scholander, P. F., Love, W. E., and Kanwisher, J. W. 1955. The rise of sap in tall grapevines. Plant Physiol. 30:93-104.

28. Severin, H. H. P. 1949. Transmission of the virus of Pierce's disease of grapevines by leafhoppers. Hilgardia 19:190-206.

29. Severin, H. H. P. 1950. Spittle-insect vectors of Pierce's disease virus II. Life history and virus transmission. Hilgardia 19:357-381.

30. Sorensen, J. T., and Gill, R. J. 1996. A range extension of Homalodisca coagulata (Say) (Hemiptera: Clypeorrhyncha: Cicadellidae) to southern California. Pan-Pacific Entomol. 72:160-161.

31. Sperry, J. S., Holbrook, N. M., Zimmermann, M. H., and Tyree, M. T. 1987. Spring filling of xylem vessels in wild grapevine. Plant Physiol. 83:414-417.

32. Zadoks, J. C. 2001. Plant disease epidemiology in the twentieth century. Plant Dis. $85: 808-816$. 